\title{
Effect of Core Stability Training on Some Physical Variables and the Performance Level on Junior Gymnast
}

\section{Dr/ Khaled Abuwarda ${ }^{1}$}

Abstract: Core stability training has had its role in improving the fitness level by strengthening body core muscles as well as its effect in improving and upgrading the level of skill performance. The research aims to identify the effect of core stability training on some physical variables and on the performance of Floor exercise and Vaulting Table. The experimental method and sample was selected by using the intentional method from the players in Suez Canal Authrioty Club of Port Fouad,. Total numbers of 12 players was divided randomly into two equal groups consisting to 6 players for each. The most important results were that the training program with added core stability exercises in the part of special physical preparation, which applied to the experimental group was more effective than training without the addition of core stability exercises, so that it led to improve the level of some physical variables - under discussion - with a higher rate.

Key words: Gymnastics \& floor exercise \& Vaulting Table \&Body core \&Core stability

\section{The Introduction And The Research Issue}

There is no doubt that Gymnastics sport is one kind of sports completely depends on large muscles like arm muscles , shoulders .The ongoing changes to the law of Arbitration Gymnastics put further burdens on the training programs makers or authors and on its development, to catch up and follow the progress. And from this we need to develop training programs. Willardson also points out that in recent years the attention of the specialists in the field of fitness has increased to the use of trunk stability exercises .William, Prentice and Daniel suggested that body core consists of a group of muscles known as PELVIC-LUMBER-HIP compels, and they consist of 29

${ }^{1}$ Faculty of Physical Education for Boys and Girls, University of Port Said 
muscles. Also the body core is the center of mass.Willardson (2008) Quinn (2005) and James (2005) they all agreed that body core stability exercises are from the methods of modern physical training of the body muscles. The basic objective of these exercises is to develop and increase the strength of the deep muscles of trunk.It is considered that the fundamental importance of body core stability training is to control and fix trunk and pelvic joint muscles.The gymnast moves in a way against the gravity, so when the gymnast doing those skills, he needs fixation of the pelvic joint and lower back .

Research Objective: The research aims to identify the Effect of Core Stability Training on Some Physical Variables and the Performance Level on Junior Gymnast under 7 years

Research Hypothesis:

- $\quad$ There would statistically significant differences between pre-post-test (tribal and dimensional measurements) of the special physical capabilities level and skills performance degree of the junior gymnast of the control group and these differences are for favor of post-test .

- $\quad$ There would statistically significant differences between pre-post-test (tribal and dimensional measurements) of the special physical capabilities level and skills performance degree of the junior gymnast of the experimental group and these differences are for favor of post-test .

- $\quad$ There would statistically significant differences between the experimental and control group in the post-test of the special physical capabilities level and skills performance degree of the junior gymnast and these differences are for favor of the experimental group .

Procedures Research methodology :The researcher used the experimental method using two groups, one experimental and the other is control.

The research sample: The sample was selected by the purposive method way from under 7 years old players of Suez Canal Authority club in Port Fouad .The sample included 12 players ,they were divided randomly to two equal groups one of them experimental and the other one 
is control. Each one of them consists of 6 players, it has been applying the same training program (attachment no.3) for the 2 groups except the body core exercises which has been applied only on the experimental group (attachment no.4) also the researcher hired 23 gymnast from outside the basic search sample but from the same community (society) for the exploratory study and the scientific transactions of the tests and the used measures.

Training program:

The researcher set up the proposed training program to develop core stability by reviewing previous studies and both specialized and science sports coaching.

The Pilot Study :

The researcher conducted the pilot study in the period from Sunday 19/1/2014 to Thursday $30 / 1 / 2014$ in order to ensure the safety and validity of the tools and devices used and ration physical skill preparation exercises and core stability exercises in which the training program involved. This was done by using a sample of 3 players from the same research Results and discussion : community and outside the basic research sample.

Basic Experiment:

Pre Tests: Pre-test conducted on basic research sample in the Hall of Suez Canal Authority Club Port Said, In the period from Monday 3/2/2014 to Tuesday 4/2/2014.

The application of the training program:

The training program applied to both control and experimental groups adding core stability exercises to the original program ,this exercises added to the part concerned with the part of physical preparation of the applicable training program to the experimental group. Where time performance of coramounte stability exercises in a week varies between 39 $\mathrm{min}$. to $126 \mathrm{~min}$. for 12 weeks in the period from Saturday 8/2/2014 to Friday 30/4/2014 (four training modules per week)

\section{Post-test :}

Conducted in the same above mentioned place and according to the same order followed in the pre test in the period from Sunday 4/5/2014 to Monday $5 / 5 / 2014$. 


\section{Table (1)}

Significant differences between the pre-post-tests in the physical variables and the level of performance on Floor exercise and Vaulting Table for the control group, $n 1=6$

\begin{tabular}{|c|c|c|c|c|c|c|c|c|c|}
\hline & \multirow{2}{*}{ Variables } & \multicolumn{2}{|c|}{$\begin{array}{l}\text { No.of } \\
\text { Ranks }\end{array}$} & \multicolumn{2}{|c|}{$\begin{array}{l}\text { Sum of } \\
\text { Ranks }\end{array}$} & \multicolumn{2}{|c|}{$\begin{array}{c}\text { Mean of } \\
\text { Ranks }\end{array}$} & \multirow{2}{*}{$\begin{array}{c}\text { computed } \\
\text { Z } \\
\text { by } \\
\text { Wilcoxon }\end{array}$} & \multirow{2}{*}{ Sig } \\
\hline & & - & + & - & + & - & + & & \\
\hline \multirow{5}{*}{ 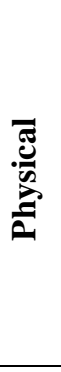 } & $\begin{array}{l}\text { handstand } 10 \\
\text { sec }\end{array}$ & 0 & 6 & 0 & 21.00 & 0 & 3.50 & -2.27 & 0.023 \\
\hline & $\begin{array}{l}\text { Running } 20 \\
\mathrm{~m}\end{array}$ & 0 & 6 & 0 & 21.00 & 0 & 3.50 & -2.44 & 0.014 \\
\hline & Pull-up & 0 & 6 & 0 & 21.00 & 0 & 3.50 & -2.44 & 0.028 \\
\hline & Push up & 0 & 6 & 0 & 21.00 & 0 & 3.50 & -2.20 & 0.028 \\
\hline & Hang $20 \mathrm{sec}$ & 0 & 6 & 0 & 21.00 & 0 & 3.50 & -2.23 & 0.026 \\
\hline \multirow[t]{2}{*}{$\frac{\bar{x}}{\infty}$} & $\begin{array}{l}\text { Floor } \\
\text { Exercises }\end{array}$ & 0 & 5 & 0 & 15.00 & 0 & 3.00 & -2.26 & 0.025 \\
\hline & Vault Table & 0 & 6 & 0 & 21.00 & 0 & 3.50 & -2.20 & 0.027 \\
\hline
\end{tabular}

Wilcoxon Tabular value at the level of statistical significance $(0.05)=2$

Data presented in table 1 indicated by the application of Wilcoxon Matched - pairs Signed Ranks Test for the significant difference between pre-post tests for the control group of some physical variables and performance level on Floor exercise and
Vaulting Table were limited between (-2.27_-2.20)at statistical significance levels ranged between (0.014-0.028) and all of them statically significant, that means the differences between the prepost-test of the control group were sincere and for the favor of post-test which indicates the improvement in these variables among the control group. 
Table (2)

.Significant differences between pre-post-test in physical variables and performance levels on Floor exercise and Vaulting Table for the experimental group .

\begin{tabular}{|c|c|c|c|c|c|c|c|c|c|}
\hline \multirow{2}{*}{\multicolumn{2}{|c|}{ Variables }} & \multicolumn{2}{|c|}{$\begin{array}{l}\text { No.of } \\
\text { Ranks }\end{array}$} & \multicolumn{2}{|c|}{$\begin{array}{c}\text { Sum of } \\
\text { Ranks }\end{array}$} & \multicolumn{2}{|c|}{$\begin{array}{c}\text { Mean of } \\
\text { Ranks }\end{array}$} & \multirow{2}{*}{$\begin{array}{c}\text { computed } \\
\text { Z } \\
\text { by } \\
\text { Wilcoxon }\end{array}$} & \multirow{2}{*}{ Sig } \\
\hline & & - & + & - & + & - & + & & \\
\hline \multirow{5}{*}{$\frac{\tilde{U}}{2}$} & $\begin{array}{c}\text { handstand } \\
10 \mathrm{sec}\end{array}$ & 0 & 6 & 0 & 21.00 & 0 & 3.50 & -2.25 & 0.024 \\
\hline & $\begin{array}{c}\text { Running } \\
20 \mathrm{~m}\end{array}$ & 0 & 6 & 0 & 21.00 & 0 & 3.50 & -2.23 & 0.026 \\
\hline & Pull-up & 0 & 6 & 0 & 21.00 & 0 & 3.50 & -2.20 & 0.028 \\
\hline & Push up & 0 & 6 & 0 & 21.00 & 0 & 3.50 & -2.20 & 0.028 \\
\hline & $\begin{array}{c}\text { Hang } 20 \\
\text { sec }\end{array}$ & 0 & 6 & 0 & 21.00 & 0 & 3.50 & -2.32 & 0.026 \\
\hline \multirow{2}{*}{$\frac{1}{\sqrt{n}}$} & $\begin{array}{c}\text { Floor } \\
\text { Exercises }\end{array}$ & 0 & 6 & 0 & 15.00 & 0 & 3.50 & -2.27 & 0.023 \\
\hline & $\begin{array}{l}\text { Vault } \\
\text { Table }\end{array}$ & 0 & 6 & 0 & 21.00 & 0 & 3.50 & -2.20 & 0.028 \\
\hline
\end{tabular}

Table 2 indicated that with the application of Wilcoxon Matched pairs Signad Ranks Test the values of computed $\mathrm{Z}$ between the pre-post tests for the experimental group in physical variables and performance level on Floor exercise and Vaulting Horse limited between (-2.20_-2.27) with statistical significance ranged between (0.023-0.028) and all of them are statistically significant which pointed out that the differences between the pre-post tests for the experimental group were true and sincere and for the favor of post-test ,this indicated the improvement of the experimental group individuals in those variables. 


\section{Table (3)}

Significant differences between both experimental and control group in post-tests in the physical variables and performance level on Floor exercise and Vaulting Table.

\begin{tabular}{|c|c|c|c|c|c|c|c|}
\hline & \multirow{2}{*}{ Variables } & \multicolumn{2}{|c|}{ No.of Ranks } & \multicolumn{2}{|c|}{$\begin{array}{l}\text { Sum of } \\
\text { Ranks }\end{array}$} & \multirow{2}{*}{$\begin{array}{c}\text { Computed } \\
\mathrm{U}\end{array}$} & \multirow{2}{*}{ Sig } \\
\hline & & Exp & Con & Exp & Con & & \\
\hline \multirow{5}{*}{.ల్ٍ } & handstand $10 \mathrm{sec}$ & 9.33 & 3.67 & 56.00 & 22.00 & 1.00 & 0.004 \\
\hline & Running $20 \mathrm{~m}$ & 9.08 & 3.92 & 56.00 & 22.00 & 2.50 & 0.009 \\
\hline & Pull-up & 9.17 & 3.83 & 55.00 & 23.00 & 2.00 & 0.009 \\
\hline & Push up & 9.00 & 4.00 & 54.00 & 24.00 & 3.00 & 0.015 \\
\hline & Hang $20 \mathrm{sec}$ & 8.75 & 4.25 & 52.50 & 25.50 & 4.50 & 0.026 \\
\hline \multirow{2}{*}{$\frac{\overline{7}}{a}$} & Floor Exercises & 9.17 & 3.83 & 55.00 & 23.00 & 2.00 & 0.009 \\
\hline & Vault Table & 8.83 & 4.17 & 53.00 & 25.00 & 4.00 & 0.026 \\
\hline
\end{tabular}

Tabular value of $U$ at the level of statistical significance $(0.05)=5$

Table 3 illustrated that computed $\mathrm{U}$ with the application of Mann-Whitney Test for the significant differences between the experimental and control group in the post tests for the physical variables and performance level on Floor exercise and Vaulting Horse were limited between (1.00-4.00) with statistical significance ranged from (0.004-0.026) and all of them statically significant (0.05) which means that the post tests of the two groups in these variables are true and for the favor of the experimental group ,and that indicates to the high level of the experimental group individuals over control group individuals in the special physical variables and performance level under search.

THE

RESULTS

DISCUSSION : Data presented in Table 5 means a significant improvement in these variables among control group members has been occurred .This due to the researcher rated program which has been applied to the control group. experimental group members has been occurred . As shown in table 7 there was significant differences between 
experimental and control group in post tests for the physical variables and skill performance of Fioor Gymnastics and Vaulting Horse where U values computed for these variables were limited between $(1.00,4.00)$ and statistically significant levels ranged between $(0.004,0.026)$.The researcher attributes this noticeable superiority of the experimental group in the physical variables.The researcher noticed that ,this superiority due to the effect of body core exercises that have been added to the private physical preparation in the private training program of the experimental group and time of performance ranged between $39 \mathrm{~min}$. to $126 \mathrm{~min}$. per week during the training program .(attachment no.3. Core stability training affected on working muscles group of the spine. These are the Erector Spinae (Fig. 1), consisting of three muscles, spinalis, longissimus and iliocostalis, which help in the movements of extension and curvature and rotation of the spine in any direction and multifidus (Fig.
2) one of the smallest, most powerful muscles, which gives support to the spine maintaining stability to the spine and assisting in the movements of back flexion, rotation on the sides and
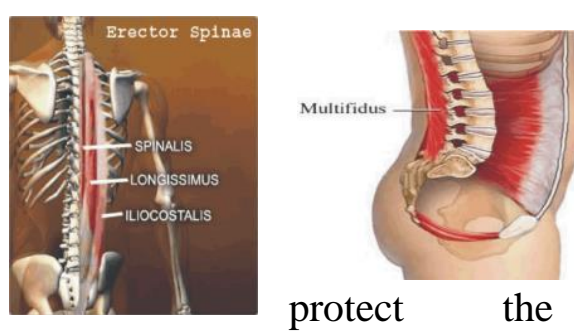

spine from injury.

Fig.1

Fig.2

Core stability training also affected on abdominal muscles Restus Abdminis ,which are extending along the abdomen,

Transverse Abdminis and the deepest layer of the abdominal wall, Externat Obliquse emerging and arise from the lateral surface and the lower ridge of eight lower ribs and Internal Obliquse, which arise from the lumbar peritoneal and the flat middle iliac crest (Fig.3), Core stability training also contributes in influencing hip flexor muscles (Fig. 4), which are found in the front part of the thigh and is responsible for 
moving the knee towards the chest (bending hip).
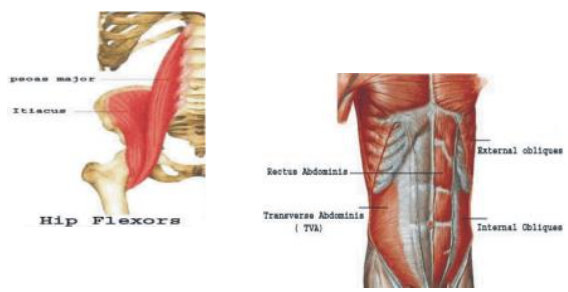

Fig.4

Fig.3

Fig.3 Core stability training also helps in strengthening Hip Adductors (Fig. 5), which in turn are divided into three types of muscles; the adductor magnus, consisting most of the medial hip part, located between the back and front hip muscles and is working to extend and relax the hip and adductor brevis which located in front of adductor magnus, behind the adductor longus and contribute to contract and adduct hip and rotate it to the medial segement.

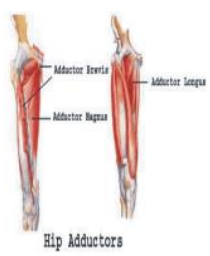

Fig.5

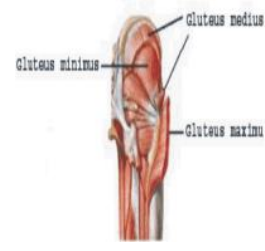

Fig.6
Fig.4 Core stability training also contributes strengthening gluteus minimus, medius and maximus muscles (Fig. 6). Gluteus minimus, medius muscle abduct and rotate hip to the medial direction, while the Gluteus maximus, which is the largest muscles of the body, extends the hip and share the work with the hip muscles to stabilize the pelvis on the femur. Therefore, these muscles contribute to the equilibrium and stability of the different static hold positions CONCLUSIONS:

- In light of the research objectives, hypotheses, within the method used and the sample, the researcher can conclude the following:

- Training program that includes exercises of the physical and skill preparation applicable to the control group had a positive effect on some physical variables and the performance level of the players on Floor exercise and Vaulting Table,where computed $\mathrm{Z}$ for these variables limited between $(-2.27,-2.20)$

- Training program that includes exercises of the physical and skill preparation in addition to 
body core training applicable to the experimental group had a positive effect on some physical variables and the performance level on Floor exercise and Vaulting Horse, where $\mathrm{z}$ values computed for these variables limited between $(-2.00,-2.27)$.

- The experimental program which includes physical and skill preparation exercises to which core stability training is added in the part of physical preparation that applied to the experimental group was more effective than without adding the same exercises These led to improve level of some physical variables and the performance on Floor exercise and Jumping in a higher rate where $U$ values computed limited between (1.00,4.00).

Recommendations:

- Based on this study, which resulted in some conclusions, References:

\section{Arabic:}

1. Ahmed Abd-Elhadi

(2010) Developing Techniques the researcher recommends the following:

- Using the training program, under discussion, on planning for Gymnastics.

- Using core stability exercises, under discussion, in training Gymnastics juniors because of their influential role in improving the level of physical capacity and the performance level under discussion.

- Emphasis on the use of core stability exercises for gymnasts in order to prevent injuries and rehabilitation assistance in returning to their previous levels.

- Emphasis on attention to strengthening body core musles as one of the complementary aspects of the fitness program.

- Conducting further similar studies to determine the effect of core stability training on variables and other age phases.

in Gymnastics Training with the use of the main Muscle Work. 
2. El-Said

Abd-

Elmaksoud (without) Sports

Training Theories ( Part 1)

Cairo .

\section{El-Said}

Elmaksoud

Training
(1994) Sports

Theories--

Fundamental aspects of the

Training Process -El Hasnaa Library Cairo.

4. Adel

Abd-Elbasir

(1998)Theories and scientific bases in modern Gymnastics training .Floor Exercises Devices,Rings, Vaulting Table.Dar El-feker El-arabi Cairo.

5. Adel

Abd-Elbasir

(1999) Athletic Training and Integration between theory and Foreign:

9. Allen, skip ::(2002), "Core Strength Training", Science Institute Sports Science Exchange Roundtable. 10. Bliss, Lisa S:(2005), "Core Stability: The Centerpiece of any Training Program", American College of Sports Medicine. practice .Book publishing center Cairo.

6. Alaa Hamed -Ehab Abd-Elmoniem ,(2006) Basic of performance in modern Gymnastics .Ammer for printing and publishing Elmansoura.

\section{Ali}

Hassouna,(2012)The effect of Body core stability training program on some health variables for athletes. $\mathrm{PhD}$, Faculty of Physical Education for BOYS , Helwan University 8. Mohamed Shehata ,(2003) Contemporary training of Gymnastics .Dar El-feker El-arabi Cairo.

\section{Eltanahi, Nagla. :}

(2011). The Effect of Swiss ball exercises on some physical and physiological variables and its relationship with Kata performance level. Journal of Physical Education and Sport, University of Pitesti citvis Actis, Issue 1, Vol. 8. Pp: 56- 
12. Fredericson, Michael, Moore, Tammara.:(2005)

Core stabilization training for middle-and long-distance runners. New Studies in Athletics, Volume: 20, Issue: 1, Pp: 25-37.

\section{James , M (:2005) .} Swiss Ball For Total Fitness . Published By Sterling Publishing Co., Inc. 387 Park Avenue South, New York .Pp: $10,11$.

14. Marshall PW. and Murphy BA.:(2005). Core stability exercises on and off a Swiss ball. Arch Phys Med Rehabilitation; 86. Pp: 242- 9.

\section{Quinn, E.: (2005,}

November 01). The Best Core

Exercises. Retrieved February 15, 2011, from About: Sports Medicine:

http://sportsmedicine.about.co $\mathrm{m} /$

16. Saeterbakken, AH, den Tillar, $R$ and seiler, S: (2011). Effect of core stability training on throwing velocity in female handball players. J Strength
Cond. Res 25 (3). Pp: $712-$ 718.

17. Stanton, R., P., Reaburn and $B$. Humphries:(2004) The effect of short term Swiss ball training on core stability and running economy, j., Strength Cond. Res. 18 (3). Pp: 522528.

18. Staff, M. C.: (2011, October 01). Core exercises: Why you should strengthen your core muscles. Retrieved December 03, 2011, from MayoClinic.com:

http://www.mayoclinic.com/ 19. Tantawi Sameh Sh, : 2011. "Effect of Core Stability Training on Some Physical Variables and the Performance Level of the Compulsory Kata for Karate Players".World Journal of Sport Sciences 5 (4):

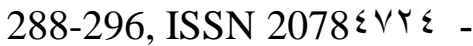

20. Tse, Michael A.:(2009). Exploring the impact of core stability on performance. Doctor of Philosophy, University of Hong Kong (Pokfulam Road, Hong Kong). 
21. William E. Prentice, Daniel D. Arnheim :(2005),"Arnheim's Principles of Athletic Training", McgrawHill (Tx)

22. Willardson JM :(2007), "Core Stability training : applications to sports conditioning programs", Physical Education Department, Eastern linois University, Journal of Strength \& Conditioning Research.

23. Willardson, Jeffrey M.: (2008). Core Stability for Athletes (7/7/2008), , PhD, CSCS, This paper was presented as part of the NSCA Hot Topic Series. All information contained herein is copyright of the NSCA. www.nsca-lift.org

\section{WEB Sites:}

24. http://www.figgymnastics.com/

25. http://www.usagymnastics.org/

26. http://www.egyptgymna stics.com-results

27. http://startingstrength.co m/articles/core_stability_rippet oe.pdf. Retrieved February 24, 2011, from Starting Strength: http://startingstrength.com/inde x.php

28. https://www.gaa.ie/conte $\mathrm{nt} /$ documents/publications /player_welfare/What_is_core_ stability_100129123941.pdf 